\title{
Proportional distribution method for estimating actual grain flow under combine harvester dynamics
}

\author{
Wang $\mathrm{He}^{\mathrm{I}^{*}}$, Bai Xiaoping ${ }^{2}$, Liang Hongbin ${ }^{1}$ \\ (1. School of Mechanical Engineering and Automation, University of Science and Technology Liaoning, Anshan 114051, China; \\ 2. Shenyang Institute of Automation, Chinese Academy of Sciences, Shenyang 110016, China)
}

\begin{abstract}
The yield monitors use a constant delay time to match the grain flow with location. Therefore, mixing and smoothing effects on the grain flow are neglected. Although constant time delay compensates for time mismatch, actual grain flow at a combine harvester head is not equal to the grain flow measured by a sensor due to the dynamics effects. In order to eliminate the dynamics effects, a new method for estimating actual grain flow, called proportional distribution (PD), is proposed. This method assumes that actual grain flow is directly proportional to the feedrate. Based on this assumption, the actual grain flow results from redistributing accumulated grain mass over a certain time according to the profile of the feedrate. The PD can avoid the dynamics effects because the feedrate is measured at a combine harvester's head. Compared with constant time delay, the proposed method can effectively estimate actual grain flow and be applied to improve the accuracy of yield maps. Keywords: grain flow, combine harvester, estimation method, proportional distribution, time delay, yield map, yield monitoring sensor
\end{abstract}

DOI: $10.25165 /$ j.ijabe.20171004.2732

Citation: Wang H, Bai X P, Liang H B. Proportional distribution method for estimating actual grain flow under combine harvester dynamics. Int J Agric \& Biol Eng, 2017; 10(4): 158-164.

\section{Introduction}

Grain flow measurement is particularly significant because it has a direct impact on site-specific yield. While clean grain flow is only measured at the exit of the clean grain elevator, it is the ideal position for grain flow measurement. Nevertheless, that location has two important drawbacks. Firstly, grain flow is not measured as soon as the crop enters the combine, which results in a delay in the measured outcome. Secondly, measurement grain flow results from the joint action of threshing and cleaning and is not equal to actual grain flow at the combine harvester head.

Received date: 2016-07-28 Accepted date: 2017-01-30

Biographies: Bai Xiaoping, $\mathrm{PhD}$, Associate Professor, research interests: software design in precision agriculture, Email: Baixiaopin@sia.cn; Liang Hongbin, PhD, Professor, research interests: control algorithm and mechanism model, Email: lianghb@hit.edu.cn.

*Corresponding author: Wang He, $\mathrm{PhD}$, Associate Professor, research interests: measurement and control technology in precision agriculture. No.185 Qianshan Middle Road, Anshan, Liaoning Province, China. Tel: +86-0412-5929782, Email: 21570453@163.com.
Numerous researchers have proposed methods to solve this problem. Previous researches have focused on a simple time delay or a first-order model for the combine harvester as a whole ${ }^{[1-3]}$. These models assume that the grain enters combine harvester and goes through combine harvester components without being disturbed until the flow is measured by the yield sensor. They rely on the assumption that shifting of the flow signal suffices for determining the actual field coordinates of yield. In recent researches, in essence, the combine harvester dynamics is of a higher order. The relationship between actual grain flow and measurement grain flow is approximated by a fourth-order linear transfer function ${ }^{[4,5]}$.

However, these linear flow models fail to reconstruct actual grain flow since combine harvester dynamics is more complex than a linear model. Other interesting researches are concerned with describing the impact of combine harvester dynamics. Boydell et al. ${ }^{[6]}$ applied the control convolution theory to recognize peanut yield variability in smaller regions. Their results showed that the deconvolution method was greater confidence than the simple time delay method. Deconvolution of the 
sensor response and the combine's internal processes would result in finding the grain flow through the combine, which could be used to generate more accurate yield maps. Characterizing variation of grain flow inside the combine and how these variations relate to yield variation was studied ${ }^{[7]}$. It was suggested that it would not be feasible to model all processes within a combine, which mechanistically determine flow rate. They made an assumption that flow rate measured by the yield sensor as a function of time $j(t)$, can be considered as a shift-invariant, linear transform of the flow rate at which crop enters combine head as a function of time, $h(t)$. Then, a convolution function can be established, which relates flow rate $j(t)$, to a characteristic function $i(t)$. This approach is a quick and inexpensive way to characterize the behavior of different combines with different settings, speed, and crops.

Whelan and McBratney ${ }^{[8]}$ attempted to better understand the dynamics of grain flow through the combine harvester by painting individual rows of grain sorghum different colors and investigating color variations in the combine harvester grain flow stream over time. They also worked to prove the convolution theory and proposed an approach to deconvoluting grain flow within a conventional combine harvester using a parametric transfer function ${ }^{[9]}$. In addition, they developed a parametric model that could better account for grain flow redistribution inside a combine harvester. The parametric model considers dispersion that is analogous to the flow of a narrow pulse of solute through a soil column ${ }^{[10]}$.

A grain flow model that effectively handles non-linear combine dynamics has not been developed by researchers yet. The correct grain flow is necessary through a deconvolution process if small cell applications are targeted, but may not be necessary for determining only the yield trends in fields, according to Whelan and McBratney ${ }^{[8]}$. However, the results are not encouraging particularly for deconvolution probably because the sensor noise has been amplified by the deconvolution process. Enhanced error due to deconvolution did not allow expected benefit from deconvolution process to prevail $^{[11]}$.

The specific objectives of this study are to: (1) develop a new method of estimating actual grain flow at the combine harvester head, and (2) investigate the results obtained by using a different method to determine actual grain flow through field experiments.

\section{Materials and methods}

\subsection{Estimation method}

Change in actual grain flow is more likely to occur without a significant change in measured grain flow because of combine harvester dynamics ${ }^{[12]}$. While actual grain flow is likely to change as the feedrate changes. The feedrate is measured at the combine harvester's head where the time delay is short and can be neglected. If feedrate is low or zero, then actual grain flow should also be low or zero. In a word, the feedrate shows a strong relationship between actual grain flow and the feedrate. In this research, we propose a new estimation method for actual grain flow, called proportional distribution (PD), which assumes actual grain flow is directly proportional to the feedrate. The relationship can be expressed by:

$$
q_{A}(t) \propto q_{F}(t)
$$

where, $q_{A}(t)$ is actual grain flow; $q_{F}(t)$ is the federate; $t$ is the time (s). Using this result, the relationship of cumulative mass through combine harvester head over a period of time $T$ is expressed as:

$$
\int_{0}^{T} q_{A}(t) \mathrm{d} t \propto \int_{0}^{T} q_{F}(t) \mathrm{d} t
$$

Equations (1) and (2) can be used to deduce the following expression:

$$
\frac{q_{A}(t)}{\int_{0}^{T} q_{A}(t) \mathrm{d} t}=\frac{q_{F}(t)}{\int_{0}^{T} q_{F}(t) \mathrm{d} t}
$$

or

$$
q_{A}(t)=\int_{0}^{T} q_{A}(\mathrm{t}) \mathrm{d} t \times \frac{q_{F}(t)}{\int_{0}^{T} q_{F}(t) \mathrm{d} t}
$$

Equation (4) can be rewritten as:

$$
q_{A}(t)=m_{A} \times \frac{q_{F}(t)}{m_{F}}
$$

where, $m_{A}$ is cumulative mass of actual grain flow over a period of time $T ; m_{F}$ is cumulative mass of the feed rate over a period of time $T$. Without consideration of grain loss, cumulative mass of actual grain flow should be equal to cumulative mass of measured grain flow over a 
period of time. Actual grain flow may be estimated by Equation (6).

$$
q_{A}(t)=m_{M} \times \frac{q_{F}(t)}{m_{F}}
$$

where, $m_{M}$ is cumulative mass of measured grain flow. As seen in Equation (6), the PD estimates actual grain flow using the data to be obtained from two sensors, so the PD can also consider as a data fusion method.

\subsection{Experiment equipment}

A CF806 combine harvester (CF806) is used as the test platform in this study. The CF806 combine harvester, with a cutting width of $4.4 \mathrm{~m}$, equipped with a feedrate sensor, an impact plate sensor, a data acquisition system and a GPS system, is able to harvest grain at the speed range from $2 \mathrm{~km} / \mathrm{h}$ to $5 \mathrm{~km} / \mathrm{h}$.

A novel grain flow sensor, installed at the top of the clean grain elevator, also using a PVDF piezoelectric film as the active element, is designed for installation on the CF806 $^{[13]}$. Amplification is enough to bring signals to an acceptable range for recording by using data acquisition system. The impact plate sensor response is recorded at a sampling frequency of $100 \mathrm{~Hz}$. A 5 VDC wet cell battery, fully independent of the combine's electrical system, powers the sensor. The sensor measures the impact force exerted on the impact plate. Many sensors use linear models to estimate grain flow $^{[14-20]}$. In contrast, experimental results exhibit an apparently nonlinear dependence of the impact force on the rate of mass flow at larger flow rates ${ }^{[21]}$. In our study, a nonlinear model was employed to estimate grain flow $^{[16]}$. The model is designed to be adaptable to varying grain conditions, such as those influenced by moisture content, by allowing free parameters of the model to be estimated through a nonlinear regression algorithm.

The feedrate sensor is a displacement sensor, which is connected to floating axle of transportation device. The sensor detects the displacement of floating axle. The installation location of the feedrate sensor is shown in Figure 1. The displacement of floating axle can indicate a thickness of grain entering combine harvester. The sensor provides a scaled 0 to $5 \mathrm{~V}$ output signals that are also sampled and saved by data acquisition system. The signals from the impact plate sensor and the feedrate sensor are filtered to improve the ratio of signal to noise. The feederate can be expressed as follows ${ }^{[22]}$ :

$$
q_{F}(t)=\rho b\left[h_{o}+h_{f}(t)\right] 2 \pi r n
$$

where, $\rho$ is the density of crop; $b$ is the width of the transportation device; $h_{o}$ is the distance between bottom of transportation device and top of chain wheel without federate; $h_{f}(t)$ is the offset distance of floating axle, $r$ is the radius of chain wheel, $n$ is the speed of chain wheel.

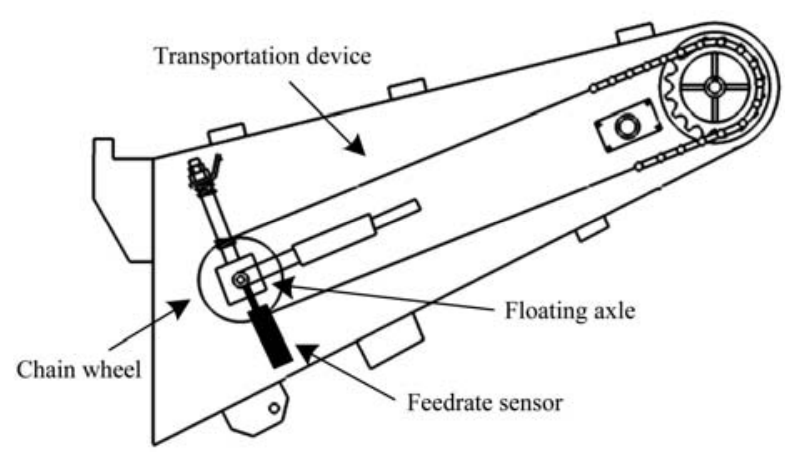

Figure 1 Installation location of the feedrate sensor

\subsection{Configuring experiment field}

To verify the proposed estimation method, field experiments are done using different configuration strips of a crop field near Jiamusi, Heilongjiang. Two types of field are created by artificial configuration. One is increasing and decreasing grain, the other is abrupt changes in grain. The similar configurations of field are also used in evaluating the response of yield monitors by Arslan and Colvin ${ }^{[23]}$.

\subsubsection{Increasing and decreasing grain}

Figure 2 shows the schema for increasing and decreasing grain. Four same strips are used to investigate the performance of the proposed estimation method. There are nine segments marked from S1 to S9 in each strip. The width of each strip to be harvested is increased or decreased by $0.9 \mathrm{~m}$ every $30 \mathrm{~m}$ to induce changes in grain flow into the combine. The distance from the CF806 starting to enter each strip is kept longer (20 m) to achieve steady ground speed. The CF806 harvests four strips without stopping over the entire strip length at ground speed of $2 \mathrm{~km} / \mathrm{h}, 3 \mathrm{~km} / \mathrm{h}, 4 \mathrm{~km} / \mathrm{h}$ and $5 \mathrm{~km} / \mathrm{h}$, respectively. When a strip is finished, the CF806 keeps driving till the outputs from impact plate sensor are approximately zero. Actual grain flow in each strip is estimated by Equation (6). 


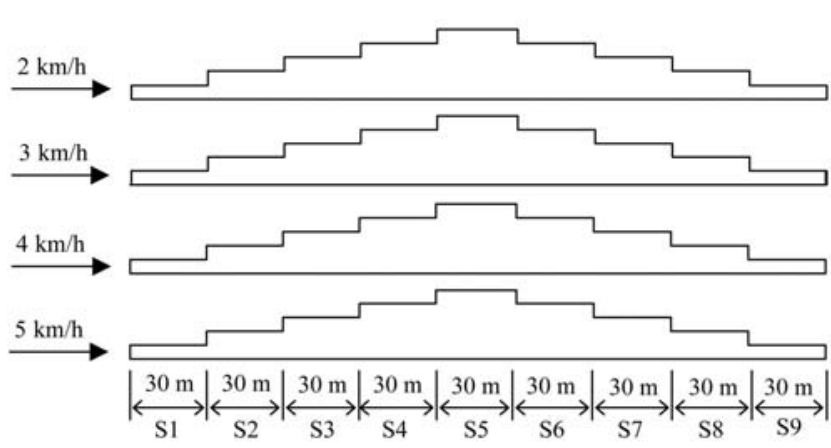

Figure 2 Increasing and decreasing grain

\subsubsection{Abrupt changes in grain}

The other type of strip is used to investigate how that proposed estimation method will respond to sudden grain changes shown in Figure 3. Four harvest strips with same dimension (150 m long $\times 4.5 \mathrm{~m}$ width) are delineated and the grain removed from four segments along harvest direction are shown in Figure 3. Removed segment lengths of $5 \mathrm{~m}, 10 \mathrm{~m}, 15 \mathrm{~m}$ and $20 \mathrm{~m}$ are created within $30 \mathrm{~m}$ segment of standing grain. The CF806 harvests four strips without stopping over the entire strip length at ground speed of $2 \mathrm{~km} / \mathrm{h}, 3 \mathrm{~km} / \mathrm{h}, 4 \mathrm{~km} / \mathrm{h}$ and

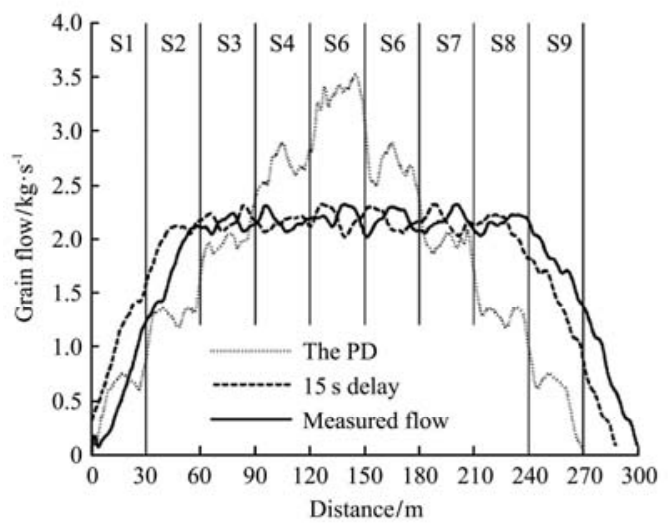

a. Harvesting at $2 \mathrm{~km} / \mathrm{h}$

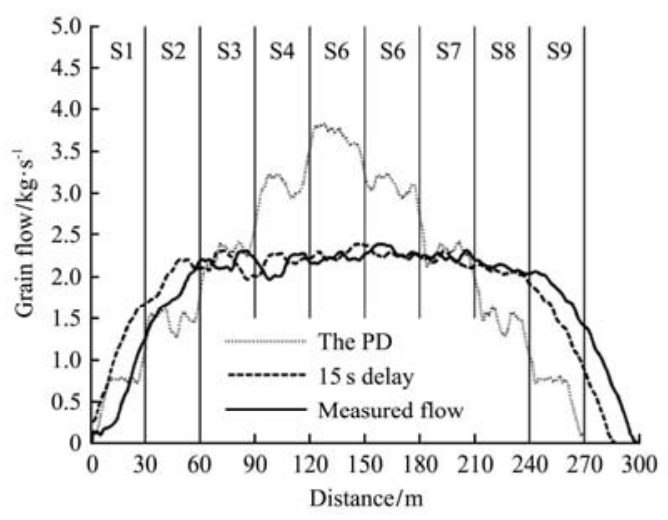

c. Harvesting at $4 \mathrm{~km} / \mathrm{h}$
$5 \mathrm{~km} / \mathrm{h}$, respectively. The distance from the CF806 starting to enter each strip is kept longer $(20 \mathrm{~m})$ to achieve a steady ground speed. When a strip is finished, the CF806 keeps driving till the outputs from impact plate sensor are approximately zero.

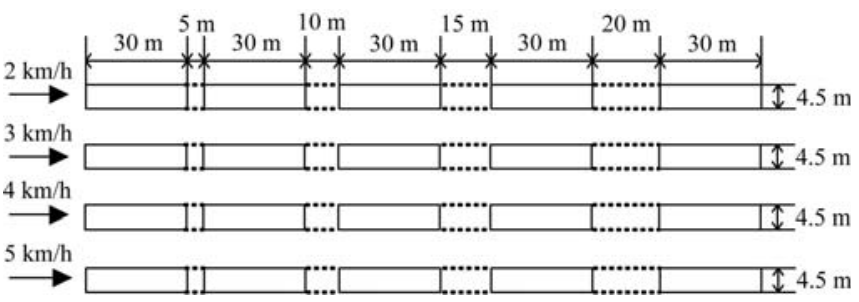

Figure 3 Abrupt changes in grain

\section{Results and discussion}

\subsection{Response to increasing and decreasing grain}

The data obtained in the field experiments are processed offline later. First, the data were preprocessed using $\mathrm{EMD}^{[24]}$, and then the actual grain flow is estimated by the PD. Comparisons between the PD and constant time delay (15 s) are made with increasing and decreasing grain. The result is plotted in Figures 4a-4d.

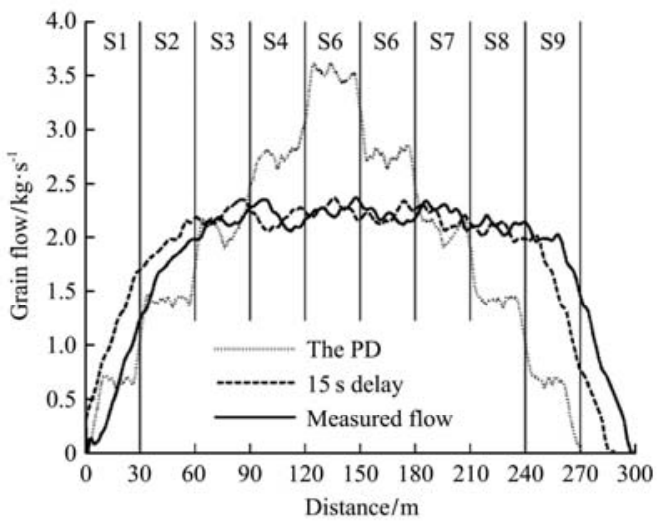

b. Harvesting at $3 \mathrm{~km} / \mathrm{h}$

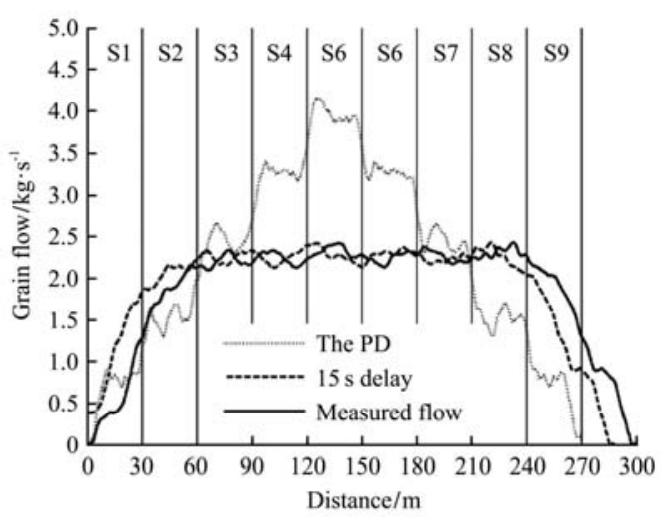

d. Harvesting at $5 \mathrm{~km} / \mathrm{h}$

Figure 4 Comparison of two methods for increasing and decreasing grain

Using constant time delay, the grain flow increases as the width of grain increases at first. However, there is no apparent change from the fourth segment to the sixth segment due to dynamics of the CF806 (Figures 4a-4d). 
By contrast, the change in grain flow is obvious using the PD. There is an $80 \%-100 \%$ increase or decrease in grain flow through the combine from the first segment to the last segment in all strips. Ground speed variations bring about fewer problems than sudden changes and/or stoppages do but are still important since they influence the time delay and grain redistribution issues ${ }^{[25]}$. Ground speed variations also influence the PD. Varying ground speed from $2 \mathrm{~km} / \mathrm{h}$ to $5 \mathrm{~km} / \mathrm{h}$ results in raised grain flow in Figures 4a-4d. For instance, the mean grain flow of the fifth segment is $3.42 \mathrm{~kg} / \mathrm{s}, 3.54 \mathrm{~kg} / \mathrm{s}$, $3.61 \mathrm{~kg} / \mathrm{s}$ and $3.75 \mathrm{~kg} / \mathrm{s}$, respectively, at the ground speed from $2 \mathrm{~km} / \mathrm{h}$ to $5 \mathrm{~km} / \mathrm{h}$.

The transitions from one segment to another are supposed to take place where the vertical lines are placed on the graph. The vertical lines dividing the segments are placed based on the position data provided by GPS system. The grain flow estimated by the PD almost increases or decreases near the vertical lines. Figure 4 illustrates the PD describing the variation of a field from the visual perspective. Since harvesting is destructive, it is not possible to measure the actual grain flow and it is necessary to rely on statistical analysis to determine which methods are superior. The PD has a higher coefficient of variation $(\mathrm{CV}, \%)$ of grain flow, which is accordant with the practical situation of increasing and decreasing grain (Table 1).

Table 1 Statistical analysis of two methods for increasing and

\begin{tabular}{ccccccc}
\multicolumn{7}{c}{ decreasing grain } \\
\hline $\begin{array}{c}\text { Speed } \\
\mathrm{km} \cdot \mathrm{h}^{-1}\end{array}$ & Method & $\begin{array}{c}\text { Min } \\
/ \mathrm{kg} \cdot \mathrm{s}^{-1}\end{array}$ & $\begin{array}{c}\text { Max } \\
\mathrm{kg} \cdot \mathrm{s}^{-1}\end{array}$ & $\begin{array}{c}\text { Mean } \\
/ \mathrm{kg} \cdot \mathrm{s}^{-1}\end{array}$ & $\begin{array}{c}\mathrm{SD} \\
/ \mathrm{kg} \cdot \mathrm{s}^{-1}\end{array}$ & $\mathrm{CV} / \%$ \\
\hline \multirow{2}{*}{2} & PD & 0.12 & 3.51 & 2.14 & 1.45 & 18.6 \\
& 15 s delay & 0.14 & 2.35 & 2.14 & 0.75 & 10.2 \\
\hline \multirow{2}{*}{3} & PD & 0.15 & 3.62 & 2.23 & 1.69 & 19.4 \\
& 15 s delay & 0.13 & 2.38 & 2.23 & 0.68 & 9.8 \\
\hline \multirow{2}{*}{4} & PD & 0.17 & 3.88 & 2.29 & 1.85 & 20.3 \\
& 15 s delay & 0.19 & 2.41 & 2.29 & 0.83 & 10.6 \\
\hline \multirow{2}{*}{5} & PD & 0.11 & 4.11 & 2.17 & 1.47 & 18.1 \\
& 15 s delay & 0.19 & 2.39 & 2.17 & 0.71 & 8.6 \\
\hline
\end{tabular}

\subsection{Response to abrupt grain}

Figures 5a-5d provides an insight into response to abrupt grain the PD has in comparison with a constant time delay (15 s). These abrupt grain changes will occur in real field conditions where there are no drive-ways or in areas with no crops. The information from these plots should be useful for observing two method's response to transients due to drastic grain.

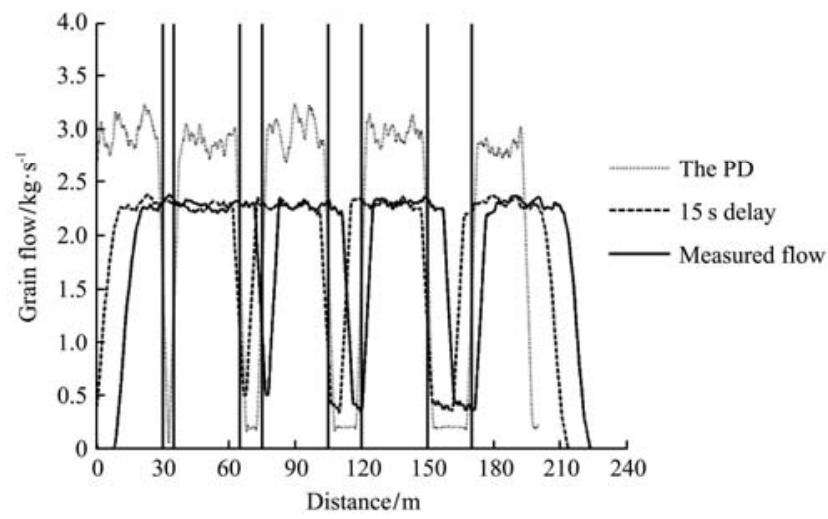

b. Harvesting at $3 \mathrm{~km} / \mathrm{h}$
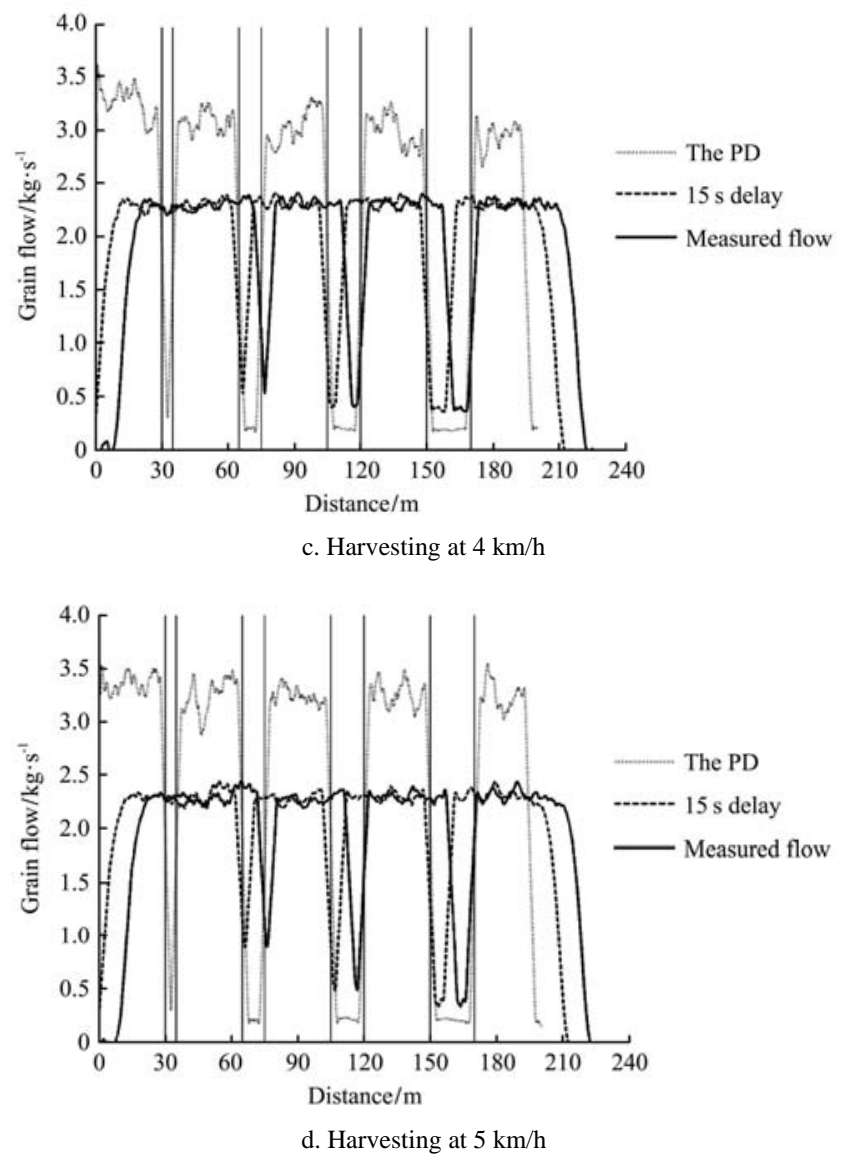

Figure 5 Comparison of two methods for abrupt grain 
The border positions of the removed segments are determined by GPS system. The PD recognizes the different-length removed segments with much greater accuracy at different ground speed (Figures 5a-5d). The $5 \mathrm{~m}$ removed segment in strips is recognized by the PD, but does not appear in constant time delay trace. The CF806 dynamics results in the $5 \mathrm{~m}$ removed grain that is obviously not using constant time delay. When the removed segments are longer than $10 \mathrm{~m}$, the grain flow estimated by constant time delay shows a distinct notch. With the increase of ground speed, constant time delay identifying the start and end point of removed segments get even worse. However, the PD has a strong robustness to identify the start and end point of removed segments. At the start of point, the grain flow falls sharply to zero, and then grain flow begins slight fluctuation around zero grain flow. At the end of point, the grain flow rapidly increases and reaches steady state.

To examine the accuracy of identifying removed segments, regression analysis of grain flow in removed segments is made. Coefficient of determination $\left(R^{2}\right)$ is calculated to quantify the performance of two methods. Figure 6 shows two methods of identifying $20 \mathrm{~m}$ removed segments at ground speed of $2 \mathrm{~km} / \mathrm{h}$. On that condition, constant time delay can achieve optimal estimation of grain flow. In Figure 6, the PD data are perfectly fit to $20 \mathrm{~m}$ removed segments with $R^{2}=0.81$, better than $15 \mathrm{~s}$ delay data with $R^{2}=0.67$.

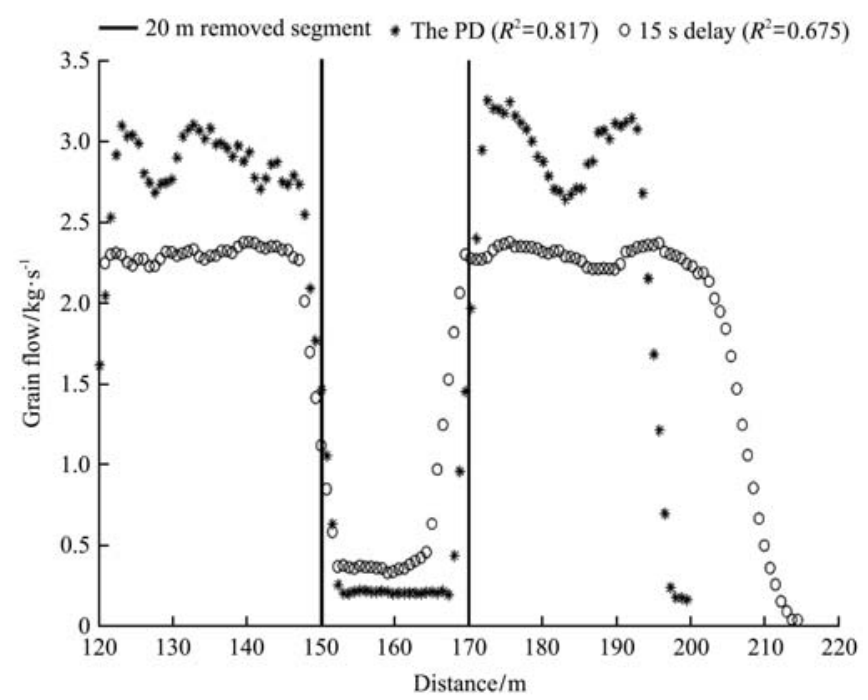

Figure 6 Identifying 20 m removed segment

Table 2 displays the $R^{2}$ of two methods for different length of removed segments at different ground speed.
The accuracy of the PD turns out to be better than accuracy of $15 \mathrm{~s}$ delay according to our statistic results. The PD seems unaffected by ground speed and length of removed segments. As ground speed increases from $2 \mathrm{~km} / \mathrm{h}$ to $5 \mathrm{~km} / \mathrm{h}$, the $R^{2}$ of $15 \mathrm{~s}$ delay decreases while a larger $R^{2}$ of $15 \mathrm{~s}$ delay is obtained at the ground speed of $2 \mathrm{~km} / \mathrm{h}$. Decreasing $R^{2}$ with increasing ground speed suggests that the accuracy of identifying removed segments is improved with lower ground speed using constant time delay.

Table 2 Comparison of accuracy in two methods used for identifying removed segments

\begin{tabular}{cccc}
\hline \multirow{2}{*}{$\begin{array}{c}\text { Speed } \\
/ \mathrm{km} \cdot \mathrm{h}^{-1}\end{array}$} & $\begin{array}{c}\text { Removed length } \\
/ \mathrm{m}\end{array}$ & PD & \\
\cline { 2 - 4 } & 5 & 0.786 & 15 s delay \\
\hline & 10 & 0.803 & 0.004 \\
& 15 & 0.791 & 0.445 \\
& 20 & 0.817 & 0.531 \\
& 5 & 0.782 & 0.675 \\
\hline 3 & 10 & 0.793 & 0.002 \\
& 15 & 0.765 & 0.326 \\
& 20 & 0.806 & 0.497 \\
& 5 & 0.782 & 0.529 \\
\hline & 10 & 0.725 & 0.275 \\
& 15 & 0.758 & 0.351 \\
& 20 & 0.799 & 0.463 \\
\hline 5 & 5 & 0.715 & 0.001 \\
& 10 & 0.753 & 0.115 \\
& 15 & 0.778 & 0.316 \\
& 20 & 0.786 & 0.418 \\
\hline
\end{tabular}

\section{Conclusions}

The combine dynamics filtering the yield variation results in reduced accuracy for varying grain flow. As a result, the smooth transitions from one segment to another in increasing and decreasing grain and the distortion from the ideal traces in abrupt grain clearly suggests that each dot on a yield map is not an accurate measure of grain yield to be tagged to a specific location in the field even if constant time delay is used to compensate. But the proposed PD effectively avoids combine harvester dynamics and accurately reflects the variation of grain flow in the field. The field experiments results indicate that the PD has provided greater accuracy than constant time delay conventionally employed. The PD could be applied to improve accuracy of yield maps, because the PD is able to estimate instantaneous grain flow at the combine harvester head. 


\section{Acknowledgement}

This project was financially supported by Nature Science Foundation of Liaoning Province, China (No.2015020128).

\section{[References]}

[1] Searcy S W, Schueller J K, Bae Y H, Borgelt S C, Stout B A. Mapping of spatially variable yield during grain combining. Transactions of the ASAE, 1989; 32(3): 826-829.

[2] Stott B L, Borgelt S C, Sudduth K A. Yield determination using an instrumented Claas combine. American Society of Agricultural Engineers. Meeting (USA), 1993.

[3] Birrell S J, Sudduth K A, Borgelt S C. Comparison of sensors and techniques for crop yield mapping. Computers and Electronics in Agriculture, 1996; 14(2): 215-233.

[4] Maertens K, de Baerdemaeker J, Ramon H, de Keyser R. $\mathrm{PH}$ - power and machinery: An analytical grain flow model for a combine harvester, Part I: Design of the model. Journal of Agricultural Engineering Research, 2001; 79(1): 55-63.

[5] Maertens K, de Baerdemaeker J, Ramon H, de Keyser R. PA-Precision agriculture: An analytical grain flow model for a combine harvester, Part II: Analysis and application of the model. Journal of Agricultural Engineering Research, 2001; 79(2): 187-193.

[6] Boydell B, Vellidis G, Perry C, Thomas D L, Hill R, Vervoort R. Dynamics of peanut flow through a peanut combine. Precision Agriculture, 1996; 805-814.

[7] Lark R M, Stafford J V, Bolam H C. Limitations on the spatial resolution of yield mapping for combinable crops. Journal of Agricultural Engineering Research, 1997; 66(3): 183-193.

[8] Whelan B M, McBratney A B. Sorghum grain flow convolution within a conventional combine harvester. Precision Agriculture'97: papers presented at the first European Conference on Precision Agriculture, Warwick University Conference Centre, UK, 7-10 September 1997. Oxford; Herndon, VA: BIOS Scientific Pub., 1997.

[9] Whelan B M, McBratney A B. An approach to deconvoluting grain-flow within a conventional combine harvester using a parametric transfer function. Precision Agriculture, 2000; 2(4): 389-398.

[10] Whelan B M, McBratney A B. A parametric transfer function for grain-flow within a conventional combine harvester. Precision Agriculture, 2002; 3(2): 123-134.

[11] Veal M W, Shearer S A, Fulton J P. Development and performance assessment of a grain combine feeder house-based mass flow sensing device. Transactions of the ASABE, 2010; 53(2): 339-348.

[12] Arslan S, Colvin T S. Grain yield mapping: Yield sensing, yield reconstruction, and errors. Precision Agriculture, 2002; 3(2): 135-154.

[13] Wang H, Hu J T, Gao L, Jia Y F. Development and optimization of a novel grain flow sensor based on PVDF piezoelectric film. Int J Agric \& Biol Eng, 2016; 9(4): 143-152.

[14] Vansichen R, Baerdemaeker J. Continuous wheat yield measurement on a combine, 1991.

[15] Borgelt S C. Sensing and measurement technologies for site specific management. Proceedings of Soil Specific Crop Management. American Society of Agronomy, Crop Science Society of America, Soil Science Society of America, 1993; pp.141-157.

[16] Reinke R, Dankowicz H, Phelan J, Kang W A. A dynamic grain flow model for a mass flow yield sensor on a combine. Precision Agriculture, 2011; 12(5): 732-749.

[17] Grisso R D, Jasa P J, Schroeder M A, Wilcox J C. Yield monitor accuracy: Successful farming magazine case study. Applied Engineering in Agriculture, 2002; 18(2): 147.

[18] Fulton J P, Sobolik C J, Shearer S A, Higgins S F, Burks T F. Grain yield monitor flow sensor accuracy for simulated varying field slopes. Applied Engineering in Agriculture, 2009; 25(1): 15-21.

[19] Burks T F, Shearer S A, Fulton J P, Sobolik C J. Combine yield monitor test facility development and initial monitoring test. Applied Engineering in Agriculture, 2003, 19(1): 5-12.

[20] Jasa P J, Grisso R D, Wilcox J C. Yield monitor accuracy at reduced flow rates. Proceedings of 2000 ASAE annual international meeting, 2000: 2575-2586.

[21] Schrock M D, Oard D L, Taylor R K, Eisele E L, Zhang N, Pringle J L. A diaphragm impact sensor for measuring combine grain flow. Applied Engineering in Agriculture, 1999; 15(6): 639.

[22] Tang Z, Li Y M, Xu L Z, Pan J, Li H C. Experimental study on wheat feed rate of tangential-axial combine harvester. Transactions of the CSAE, 2012; 28(5): 26-31. (in Chinese)

[23] Arslan S, Colvin T S. An evaluation of the response of yield monitors and combines to varying yields. Precision Agriculture, 2002; 3(2): 107-122.

[24] Wang H, Hu J T. Grain flow signal reduction noise using EMD. International Agricultural Engineering Journal, 2015; 24(2): 152-158.

[25] Robert P C. Site-specific management for agricultural system. American Society of Agronomy-Crop Science Society of America-Soil Science Society of America, 1995. 